\title{
Numerical and experimental analysis of thermal penetration depth in bare reinforced concrete structures during fire accidents
}

\author{
Luca Antonio Tagliafico ${ }^{1, *}$, Paolo Cavalletti ${ }^{1}$, Alessandro Cavalletti ${ }^{1}$, Chiara Marafioti $^{1}$, \\ Francesco Poma ${ }^{2}$, and Enrico Sterpi ${ }^{3}$ \\ ${ }^{1}$ DIME/TEC, Via all'Opera Pia 15A, University of Genoa (Italy) \\ ${ }^{2}$ Pergenova S.C.p.A., Via Renata Bianchi 40, Genoa (Italy) \\ ${ }^{3}$ SGE Service S.r.1., Via Roma 3/5, Genoa (Italy)
}

\begin{abstract}
This work faces the problem of fire resistance and temperature penetration depth in reinforced concrete under construction subjected to fire. Indeed, the design approaches always neglect the fire-induced effects on the structures under construction. In current applications, a lot of information about working boundary conditions during fire, actual material parameters and geometrical details lacks. The paper presents an original approach for the case study of a vertical reinforced concrete element (a stack under construction of the new bridge "Viadotto Polcevera", Genoa) subjected to a fire accident. Lacking information was retrieved and integrated following a multi-reference approach (numerical simulation, design and operational data, norms). The critical areas of the stack, identified by means of a simplified numerical model, were compared to samples of materials extracted from the construction site and tested in laboratory. Particular attention was given to the model sensitivity to data uncertainties about component geometry, material thermophysical properties and possible thermal effects due to the reinforcement bars extruding from the cast of concrete, acting like fins. The very good agreement between the model and experimental data allowed to identify the minimum volume of stack to be demolished and rebuilt with a significant saving in time and money.
\end{abstract}

\section{Introduction}

The design of structural systems usually includes the fire load in their final configuration [1-2]. The applicable mandatory codes have been extrapolated from theoretical and practical references, which allow analyses at different levels of complexity of the fire resistance. For instance, simple approaches can be adopted for single components while more articulated ones are required for the fire resistance of global structure.

When fire analyses are performed, the usual calculation methods assume as operating conditions that the reinforcing bars of Reinforced Concrete (RC) elements are enclosed in an adequately thick cast of concrete.

\footnotetext{
*orresponding author: tgl@ditec.unige.it
} 
In general, the design approach can be divided into 7 steps [3]:

1) identification of the functional requirements of the building;

2) drafting of the outline of the structure;

3) first endorsement of the main elements of the structure based on a preliminary evaluation of the stresses;

4) accurate evaluation of the loads acting on the structure;

5) execution of the structural analysis to determine the internal actions and the stresses;

6) verification of the first design step to check if the strength and rigidity of the elements of the supporting structure are adequate;

7) repetition of the previous phases until the verified structure is obtained.

Correctly sized concrete structures show a good mechanical response in the event of fire.

Fire induced structural collapse, especially for RC structures, is an unusual event [4-5]. Indeed, there are several cases in which, even following serious fires, RC structures have been repaired and put back into operation [6]. However, fire induced degradation can result in a permanent loss of strength and serviceability, mainly near the part of the structure exposed to the fire. In particular, the region subjected to strong variations in temperature experiences damages, with reduction of the structural capacity and useful life [7]. The depth of this region is also known as thermal wave propagation depth; this is a key parameter to identify the damaged zones. In such zones a strong variation of temperature-dependent material properties is evidenced, for both thermal (e.g. diffusivity of concrete) and mechanical (e.g. compression strength) point of view.

An accurate evaluation of residual capacity is necessary to design the proper interventions to repair fire damaged concrete structures within the limits of minimum cost in materials and time [8]. What to do instead if the structure suffered fire damage during construction with steel reinforcing bars directly exposed to heat?

Normally, two main scenarios can be identified in this context: moderate damage (the site did not have high fire loads) or severe damage.

During a fire, very few experimental information is available due to the urgency to extinguish the fire and the absence of proper instrumentation "on-board" of the structures under construction. With regard to particularly important RC structures, thermal sensors are located inside the cast to have a control on the internal temperatures during the concrete hardening. Nevertheless, the maximum measurable range of these sensors is about $200 / 250{ }^{\circ} \mathrm{C}$, so, in case of fire, no meaningful temperature can be measured (e.g. the maximum temperatures reached in the concrete in several locations). For these reasons, the most common approach consists in the demolition of the damaged elements. However, for some structures this solution is economically and time-scheduling unviable, so unconventional approaches must be used to study the effect of the fire on the structure in order to limit demolitions and reconstructions.

In the available scientific literature, such "hybrid" situations are not generally discussed as they concern a modest and uncommon percentage of cases, when compared with the existing structures or those under construction. Fortunately, fire-accidents within the building sites are not common. Few data are available, so numerical analyses on simplified models have to be performed to give fast and reliable answers and to minimise the delay of the construction schedule. In this case, excessively refined models would be useless due to their long-time development, while really short time span is available to make the decision. Onsite investigations must also be relatively simple and quick to have the main mechanical and 
chemical characteristics on which the appropriate checks can be carried out. Significative references on these aspects can be found in [9-11].

\section{Case study: fire on stack 13}

During the construction of the new bridge "Viadotto Polcevera" that will replace the "Morandi Bridge" in Genoa, a large fire has affected the stack 13 of the new structure (Figure 1). It happened at 5.20 a.m. on December, $31^{\text {st }} 2019$ and it took about three hours to the Fire Brigade and the Police to extinguish the fire and secure the area. The following photos show the stack during and after the fire-accident.
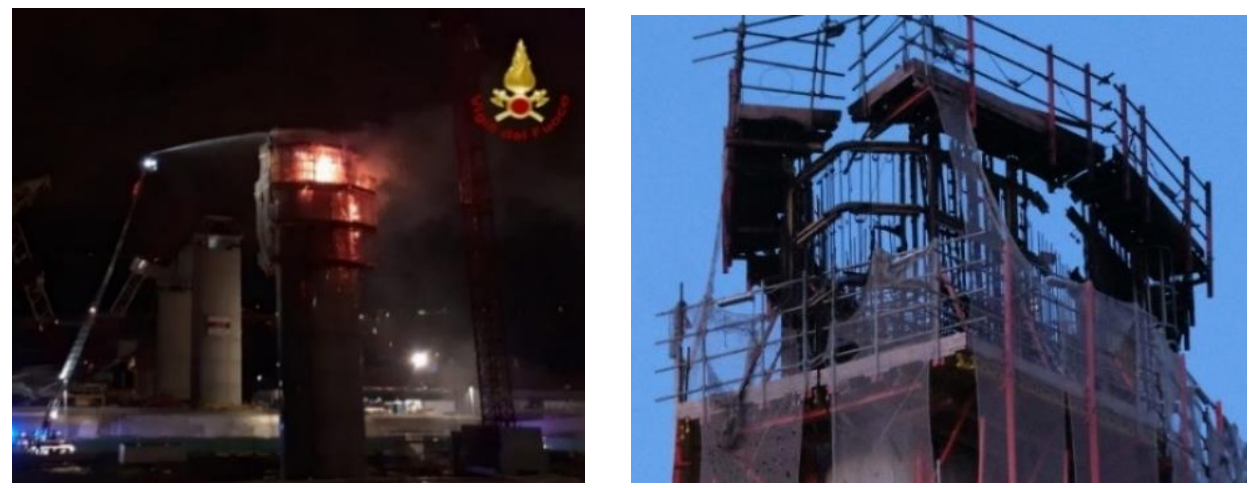

Fig. 1. Photos during and after the fire accident on stack 13, [12-13].

The problem to be faced was to establish if and at what extent the damaged stack should have been replaced and how much could have been reused. This task was accomplished by coupling numerical and experimental analysis, as described in the following paragraphs.

\section{Numerical model assembly}

The sections below briefly resume the main steps and assumptions adopted to create the numerical model of the bridge stack: the geometry, the fire simulation and the relevant boundary conditions. The commercial code COMSOL 5.3® has been employed [14].

The fire broke out on the top of the stack, near the pier cap on which the temporary metal scaffolding to support the concrete casting was laid. It enveloped the surrounding wooden formworks as well as the uncovered horizontal/vertical bars extruding from the concrete. More details on the fire can be found in the specific section about the fire model choice. The stack section is elliptical and hollow, and it can be divided into four main regions (Figure 2). 


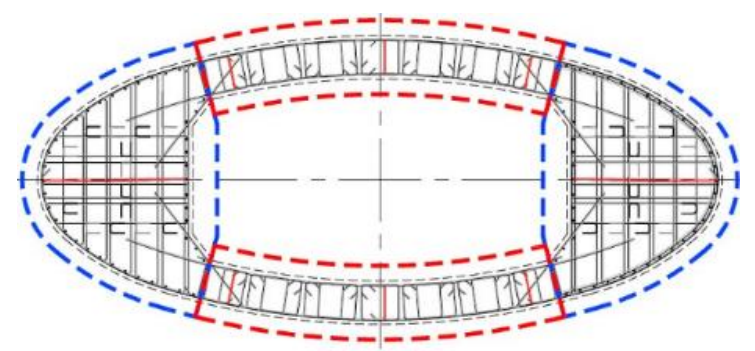

Fig. 2. The elliptical section corresponding to the pier cap of the stack and the symmetry axes. Two structure pairs are identified, in blue and red respectively.

Two main axes of symmetry can be identified. Only the red dashed part has been considered, because it represents the thinnest (critical) portion of the structure. Indeed, this area is the most susceptible part of the structure to thermal variations induced by the fire, since the thickness of concrete is lower than in the remaining part of the section.

Based on the symmetry of the problem and the reduced curvature of the studied portion several simplifying assumptions are made:

- Geometry:

○ rectangular section, neglecting the modest curvature;

- limit the study to a volume equal to a quarter of the red region: this section shows even further symmetries which allow to consider a smaller part of the structure;

$\circ$ the volume is $5 \mathrm{~m}$ in height. This hypothesis shall be considered valid and verified at the end of the elaboration, if the stack borders have no influence on the results obtained.

- Material thermophysical properties:

thermophysical properties variation with temperature refers to the studies available in scientific literature. The little information on the peculiar materials used (C35/45 concrete and $\mathrm{B} 450 \mathrm{C}$ steel) drove this choice. In particular, the temperature dependent curves shown in Appendix A have been implemented in the model. Where necessary, piecewise linear approximation of the curves was introduced. In addition, the stresses induced by the thermal gradients have been neglected and no resistance criterion has been adopted, modelling the two materials (concrete and steel) as a continuous volume. In other words, the model does not account for cracks and ruptures which might occur for instance at the interface between steel and concrete, due to the stresses caused by the thermal gradients.

- Sizes:

O total thickness equal to $60 \mathrm{~cm}$ and concrete cover $6 \mathrm{~cm}$ thick;

o reinforcement bars: vertical and horizontal bars as well as stirrups can be identified. As far as the purposes of the present study are concerned, only the vertical bars have been considered. They are partially drowned in the concrete and they represent fins increasing the propagation depth of the thermal wave. The remaining steel bars, completely bare, have been neglected since their contribution to the thermal propagation is minimal. Moreover, each vertical bar has been modelled in first approximation as a unique, continuous element with no superposition regions;

- metal scaffolding to support the concrete cast:

- $27 \mathrm{~cm}$ thick; 
- supported by means of a set of IPE 270 beams properly cantilevered into the walls in reinforced concrete.

This item has been neglected in the present work, although it might influence locally the propagation depth. The conclusions provide further considerations about this assumption.

Figure 3 shows the COMSOL geometrical model built following the above-mentioned assumptions.

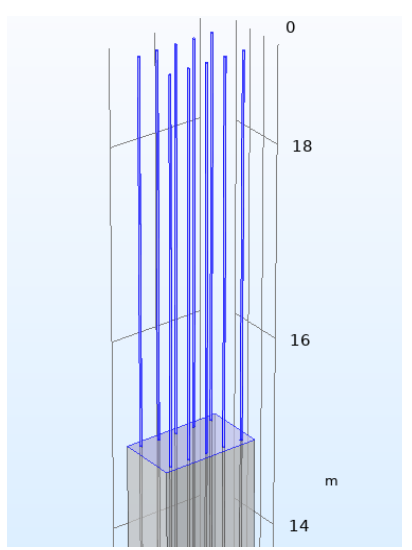

a)

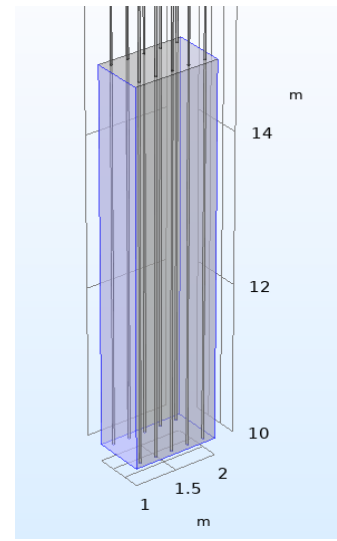

b)

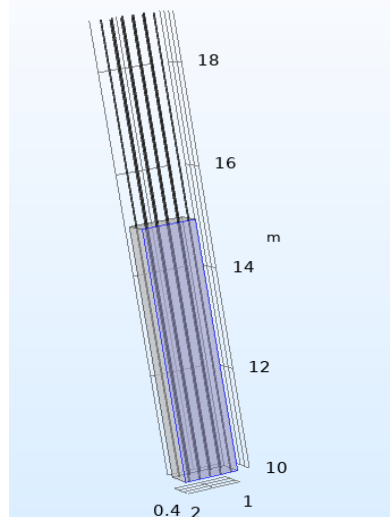

c)

Fig. 3. General overview of the model.

\subsection{Choice of the fire curve}

No precise information concerning the fire, or the climate is available. The only information is that the temperatures exceeded $1000{ }^{\circ} \mathrm{C}$ and the fire lasted more than 45 minutes. No other data could be collected, such as wind velocity. In fact, the wind direction (O-E) could be determined by means of the carbonated scaffoldings. However, no velocity record is available and therefore this aspect has been neglected. Therefore, the numerical model has been implemented with a standard fire curve ISO834 [15]. The main reasons of this choice are: i) the ISO834 curve is associated to the burning of cellulosic materials (e.g. the wooden formworks) and ii) the simulated temperatures are higher than the ones obtained for instance from the fire curve referred to external environment, giving much more severe conditions. The fire extinction phase has been neglected, since the cooling phase has negligible effects on the evaluation of the maximum propagation depth.

\subsection{Boundary and initial conditions}

The boundary conditions are summarized as follows:

- convection and radiation applied to the bare part of the rods and to the upper surface of the concrete block (marked in blue in Figure 3a). These materials are subjected to an external environment with time dependent temperature, defined by means of the ISO834 standard fire curve, lasting for 60 minutes. Indeed, the photos taken (e.g. Figure 1) show that the fire broke out on the top of the stack, just on the pier cap;

- $\quad$ symmetry boundary condition: applied to the surfaces marked in blue in Figure $3 \mathrm{~b}$ to restore the symmetry of the problem;

- convection and radiation on the external and internal surfaces (facing the hollow section of the stack) of the concrete volume (marked in blue in Figure 3c); 
- the convective thermal heat transfer coefficients have been computed using the relations available in literature and in accordance with UNI EN1991.

As far as the initial condition is concerned, the initial stack temperature has been assumed uniform an equal to the external temperature of $6{ }^{\circ} \mathrm{C}$, corresponding to the temperature during the night of $31^{\text {st }}$ December 2019 in Genoa, as registered from local weather station.

\section{Results}

The convergence analysis of the mesh is omitted here for sake of brevity using meshes with errors lower than $5 \%$. The results reported have been obtained performing a transient analysis from 0 to 60 minutes with 2 minutes time-step. Figure 5 shows the trend of the isotherms corresponding to four significative time steps (2, 20, 45 and 60 minutes respectively):

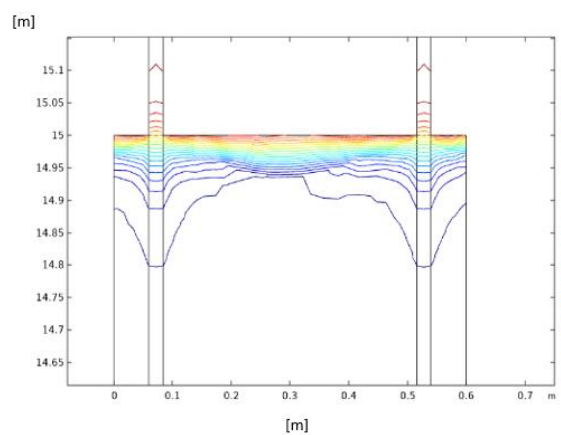

a) 2 minutes

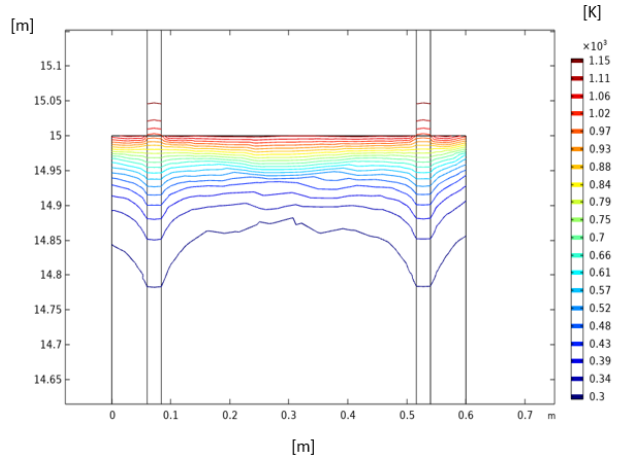

c) 45 minutes
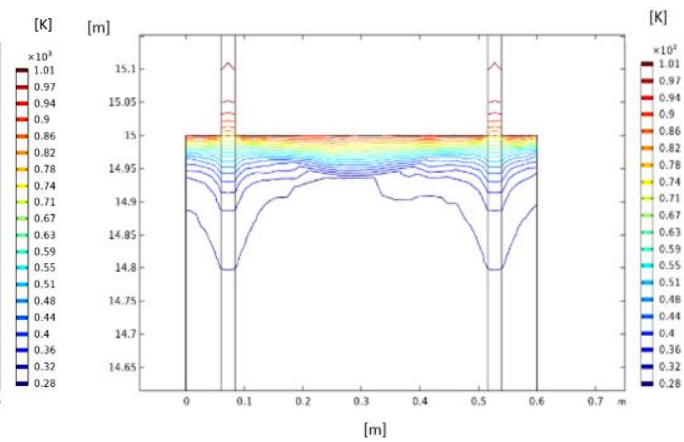

b) 20 minutes

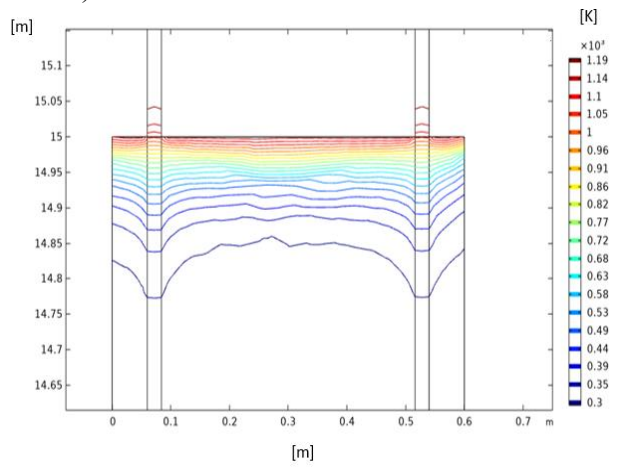

d) 60 minutes

Fig. 4. Transversal section of the model, isotherms $[\mathrm{K}]$ at different time steps at different depths. Two vertical rods extrude from the concrete block into the surrounding environment.

In the early minutes during the fire (Figure 4a), the presence of steel rods is not significative as the distribution in temperature is almost uniform. Then, after few minutes, the bars start working as thermal fins determining a high jump in temperature in the surrounding area (Figure 4b). The concrete around the steel contrasts the widening of the thermal wave which mainly propagates in depth (along the steel). Then (Figures $4 \mathrm{c}$ and $4 \mathrm{~d}$ ), the trend remains almost unchanged as the more superficial sections of the model have reached a uniform temperature (horizontal isotherms) while deeper the same jump in the temperatures can be 
appreciated. In conclusion, the assumed height of $5 \mathrm{~m}$ for the volume is correct, since the results are not influenced by the lower boundary of the model. Correctly, the isotherm approaching the lateral surfaces show different slopes, because of the different convective heat transfer coefficients adopted on the external and internal side.

At the end of the simulation ( 60 minutes), at a depth of about $15 \mathrm{~cm}$, the temperatures reached are about $350 \mathrm{~K}\left(77^{\circ} \mathrm{C}\right)$ while at a depth $20 \mathrm{~cm}$ the temperature is about $300 \mathrm{~K}\left(27^{\circ} \mathrm{C}\right)$.

So, the main damaged zones of the RC structure can be identified based on reached temperatures (Figure 5). The maximum temperatures have been reached within $10 \mathrm{~cm}(15.0$ $\mathrm{m}$ to $14.9 \mathrm{~m})$, in the range $1100 \mathrm{~K}\left(827^{\circ} \mathrm{C}\right)-680 \mathrm{~K}\left(407^{\circ} \mathrm{C}\right)$, (red area), while the region between $10 \mathrm{~cm}$ and $20 \mathrm{~cm}$ reached quite high thermal levels in the range $680 \mathrm{~K}\left(407^{\circ} \mathrm{C}\right)$ $370 \mathrm{~K}\left(97^{\circ} \mathrm{C}\right)$ (brown area).

During a fire, the concrete undergoes to different chemical reactions:

- initial heating up: a first evaporation of the free water contained in the porosity of the concrete occurs;

- when the temperature of about $350{ }^{\circ} \mathrm{C}$ is reached, a decomposition of the calcium oxide within the concrete matrix is triggered;

- $\quad$ exceeding $500{ }^{\circ} \mathrm{C}$, a decomposition of the hydrated phase of the calcium silicates takes place.

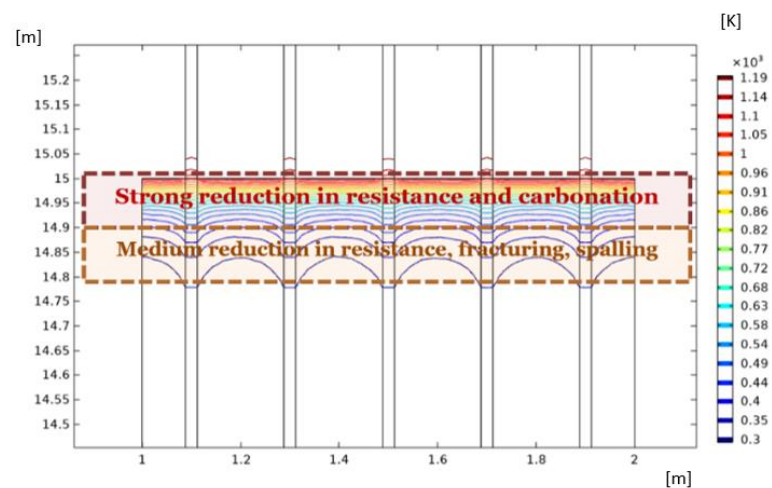

Fig. 5. Isotherms $[\mathrm{K}]$ after 60 minutes of fire and identification of the main damaged zones.

These transitions lead to an increase in the porosity of the concrete and a consequent reduction in resistance. Therefore, the extraction of concrete cylinders from carbonated sample is one of the simplest tests that can be performed. The mechanical resistance of these cylinders can be tested in order to check potential reductions of the future durability and strength of the structure, compared to the design conditions. Figure 6 shows how compressive strength in concrete decreases after the exposure to high temperatures [16-19], evidencing the corresponding expected mechanical characteristics in the case study. 


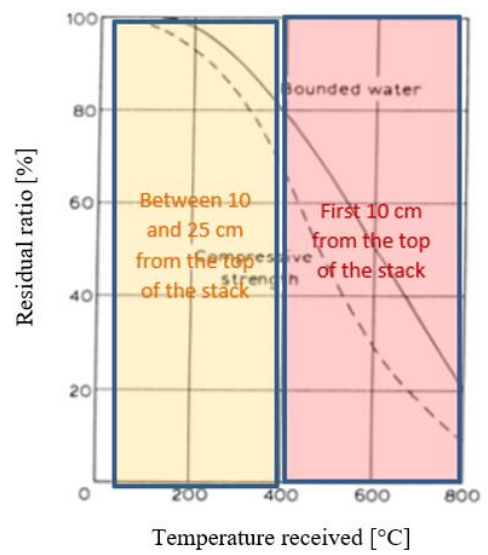

Fig. 6. Residual relative compressive strength of concrete as a function of temperature [19]. On the graph the specific zones of the stack analysed in the present case study are reported.

Therefore, depending on the type of fire, it is to be expected that all parts directly exposed to the fire brazier will have a reduction in mechanical strength and chemical alteration. Unprotected steel undergoes deformation effects due to direct exposure to fire and temperature. It gets covered with the combustion products and it experiences hardening effects caused by the thermal shock consequent to the abrupt water-cooling during fire extinction.

From the mechanical point of view, the tensile test is the simplest way to verify if the steel undergone an alteration for inclusion. The ratios $\frac{f_{y}}{f_{\text {ynom }}}$ and $\frac{f_{t}}{f_{y}}$ after the fire are compared with those of the same reinforcements before the fire. $f_{y}$ and $f_{y n o m}$ are respectively the effective and nominal yield strengths while $\mathrm{f}_{\mathrm{t}}$ represents the ultimate tensile strength. $\mathrm{A}_{\mathrm{gt}}$ represents the total elongation (in percentage) under the maximum load.

By in situ tests (Tables 1 and 2), a drop below the unit in the ratio between effective and nominal yield stress can be appreciated, and therefore the ratio between breaking strength and breakdown generally rises above 1.37 .

Table 1. Steel properties determined by means of the tensile test before the fire accident.

\begin{tabular}{|c|c|c|c|c|c|c|c|}
\hline $\begin{array}{l}\text { Diameter } \\
\phi[\mathrm{mm}]\end{array}$ & $\begin{array}{l}\text { Equivalent } \\
\text { diameter } \\
\phi_{\text {eq }}[\mathrm{mm}]\end{array}$ & $\begin{array}{l}\text { Area Aeq } \\
{\left[\mathrm{mm}^{2}\right]}\end{array}$ & $\begin{array}{l}\text { Yield } \\
\text { strength } \\
\text { fy }_{\mathbf{y}}\end{array}$ & $\begin{array}{l}\text { Breaking } \\
\text { strength } \mathbf{f}_{\mathbf{t}} \\
{\left[\mathbf{N} / \mathbf{m m}^{2}\right]}\end{array}$ & $\frac{f_{y}}{f_{\text {ynom }}}$ & $\frac{f_{t}}{f_{y}}$ & $\begin{array}{l}\text { Agt } \\
{[\%]}\end{array}$ \\
\hline 22 & 21,87 & 375,37 & 539,79 & 633,38 & 1,20 & 1,17 & 8,3 \\
\hline
\end{tabular}

Table 2. Steel properties determined by means of the tensile test after the fire accident.

\begin{tabular}{|c|c|l|l|l|l|c|c|}
\hline $\begin{array}{l}\text { Diameter } \\
\boldsymbol{\phi}[\mathbf{m m}]\end{array}$ & $\begin{array}{l}\text { Equivalent } \\
\text { diameter } \\
\phi_{\text {eq }}[\mathbf{m m}]\end{array}$ & $\begin{array}{l}\text { Area } \\
\mathbf{A}_{\text {eq }} \\
{\left[\mathbf{m m}^{\mathbf{2}}\right]}\end{array}$ & $\begin{array}{l}\text { Yield } \\
\text { strength } \\
\mathbf{f}_{\mathbf{y}} \\
{\left[\mathbf{N} / \mathbf{m m}^{2}\right]}\end{array}$ & $\begin{array}{l}\text { Breaking } \\
\text { strength } \mathbf{f}_{\mathbf{t}} \\
{\left[\mathbf{N} / \mathbf{m m}^{\mathbf{2}}\right]}\end{array}$ & $\frac{\boldsymbol{f}_{\boldsymbol{y}}}{\boldsymbol{f}_{\boldsymbol{y n o m}}}$ & $\frac{\boldsymbol{f}_{\boldsymbol{t}}}{\boldsymbol{f}_{\boldsymbol{y}}}$ & $\begin{array}{l}\mathbf{A}_{\mathrm{gt}} \\
{[\mathbf{\%}]}\end{array}$ \\
\hline 22 & 21,07 & 348,41 & 321,26 & 499,83 & 0,71 & 1,56 & 16,5 \\
\hline 22 & 21,17 & 351,75 & 349,54 & 535,39 & 0,78 & 1,53 & 19,0 \\
\hline 22 & 21,75 & 371,50 & 368,13 & 518,02 & 0,82 & 1,41 & 17,1 \\
\hline
\end{tabular}


Generally, the breaking / yield ratio must be between 1,13 to 1,37 , in this case the ratio grows up 1,37 .

The experimental tests led on concrete samples (Figure 7) show very good agreement with the prediction reported in Figure 5: the sprinklings of phenolphthalein have revealed a carbonated region within the first $8-10 \mathrm{~cm}$ depth while the lower parts resulted unaltered.

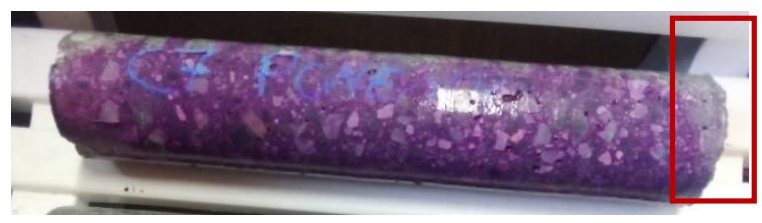

Fire exposure

Fig. 7. Experimental tests on a concrete sample. The area in violet is representative of carbonated concrete. Total length of the carbonated zone is in the range $8 \mathrm{~cm}-10 \mathrm{~cm}$.

\section{Conclusions and future developments}

In this work, the relevance of the depth for the thermal wave propagation inside reinforced concrete structures has been analysed. The numerical results obtained by means of a simplified numerical model built in COMSOL 5.3 show a very good agreement with the samples extracted and tested. Indeed, the chemical and mechanical variations able to locate severe high-temperature exposure of the extracted samples agree in location with the corresponding temperature profiles theoretically calculated. This agreement provides an indirect assessment for the use of standard ISO834 fire curve and validates the simplifying hypothesis assumed. The model leads to significative and reliable results even neglecting the strains induced by thermal variations and their effects on the RC concrete. Moreover, a clear link between numerical calculation (expressed in terms of temperature) and experimental results (expressed by means of the mechanical and chemical changes in the material due to high temperature exposure) has been highlighted.

Future developments concern the influence of high conductive structural elements (such as the top steel plate and the several steel beams included in the stack), in order to assess their influence on the thermal propagation inside the structure. The new full results shall be used to validate the present simplified model, which could become a standard reference procedure for the analysis of this kind of fire-accidents.

\section{References}

1. UNI EN 1992-1-2 Eurocode 2: design of concrete structures. Part 1-2: General rules structural fire design. Commission of European Communities, Brussels, Belgium The European Union Per Regulation 305/2011, Directive 98/34/EC, Directive 2004/18/EC (2004) 2. ASTM E119 Standard test methods for determining effects of large hydrocarbon pool fires on structural members and assemblies. American Society for Testing and Materials, West Conshohocken, PA (2008)

3. A. H. Buchanan, "Structural Design for Fire Safety, Second Edition", John Wiley \& Sons (2016) 
4. J. Beitel, N. Iwankiw, "Historical survey of multi-story building collapses due to fire", Fire Prot. Eng. pg. 42-48 (2005)

5. A. Tovey, R. Crook, "Experience of fires in concrete structures" Vol 20. Detroit: evaluation and repair of the damage to concrete, Special Publication SP 92, American Concrete Institute (1986)

6. A. Benedetti, E. Mangoni, "Damage Assessment in Actual Fire Situations by Means of Non-Destructive Techniques and Concrete Tests", 2005, 2nd Workshop "Fire Design of Concrete Structures: What now? What next?". Fib. T.G. 4.3. Published by Starrylink (Brescia), Milano, Italy, pg. 231-239 (2004)

7. P. Cavalletti, C. Pisoni "Modelli di calcolo per la valutazione degli effetti di incendio su elementi strutturali di comune impiego in edilizia", rapporto interno DINE EGR/20 (1992)

8. A. Agrawal, V.K.R. Kodur, “A Novel Experimental Approach for Evaluating Residual Capacity of Fire Damaged Concrete Members”, Fire Technol. 56, pg. 715-735 (2020)

9. M.R. Khan, R. Royles, "Post Heat Exposure Behaviour of Reinforced Concrete Beams", Mag. of Conc. Res., vol 38 n. 135 (1986)

10. R. Felicetti, "The drilling Resistance test for the Assessment of the Thermal Damage in concrete", Proc. Of the Workshop "Fire Design of Concrete Structures: What now? What next?”. Fib. T.G. 4.3. Starrylink (Brescia), Milano, Italy, pg. 231-239 (2004)

11. A. K. Pandey, M. Biswas, "Damage Detection on Structures Using Changes in Flexibility", Jour. of Sound and Vib., vol 169, Issue 1, pg. 3-17 (1994)

12. http://www.vigilfuoco.it/aspx/notizia.aspx? codnews $=62708$ access date 30/05/2020

13. https://genova.repubblica.it/cronaca/2020/01/05/news/_ponte nel_cantiere_violata_la_s icurezza scatta 1 inchiesta-244976001/access date 30/05/2020

14. https://www.comsol.eu/release/5.3 COMSOL software version 5.3 access date $30 / 05 / 2020$

15. UNI EN 1991-1-2: Eurocode 1: Actions on structures - Part 1-2: General actions - Actions on structures exposed to fire. The European Union Per Regulation 305/2011, Directive 98/34/EC, Directive 2004/18/EC (2002)

16. A.M. Neville, "Properties of concrete - 4th edition”, Pearson Prentice Hall (2006)

17.W. Zi, Z. Yu, "Durability evaluation of post-fire concrete structure based on carbonation," Int. Conf. on Cons. Electr., Comm. and Net. (CECNet), XianNing, pp. 11751177 (2011)

18. M. Iuorio, L. Pascoli, "Comportamento al fuoco del calcestruzzo", In Concreto September ATECAP, (2012)

19. V. Babrauskas, D. Drysdale, S.J. Grayson, U. Schneider, "Repairability of Fire Damaged Structures", Fire saf. Jour., vol 16, pg. 251-338 (1990)

20. K. Miłkowska-Piszczek, M. Korolczuk-Hejnak, "An Analysis of The Influence of Viscosity on The Numerical Simulation of Temperature Distribution, as Demonstrated by the CC Process", Archives of Metallurgy and Materials. 58. 10.2478/amm-2013-0146 (2013) 21. UNI EN 1993-1-1: Eurocode 3: Design of steel structures - Part 1-1: General rules and rules for buildings, The European Union Per Regulation 305/2011, Directive 98/34/EC, Directive 2004/18/EC (2005)

22. T. Z. Harmathy, L. W. Allen, "Thermal Properties of Selected Masonry Unit Concretes", Jour. Proc., vol. 2, pg. 132-142 (1973)

23. U. Schneider, C. Diererichs, C. Ehm, "Effects of Temperature on Steel and Concrete for PCRV $\backslash u 2019$ s", Nuc. Eng. Des., vol. 67, pg.245-258 (1981) 
APPENDIX A - Thermophysical properties of the materials (steel B450C and concrete $\mathrm{C} 35 / 45$ ) implemented in the numerical model.

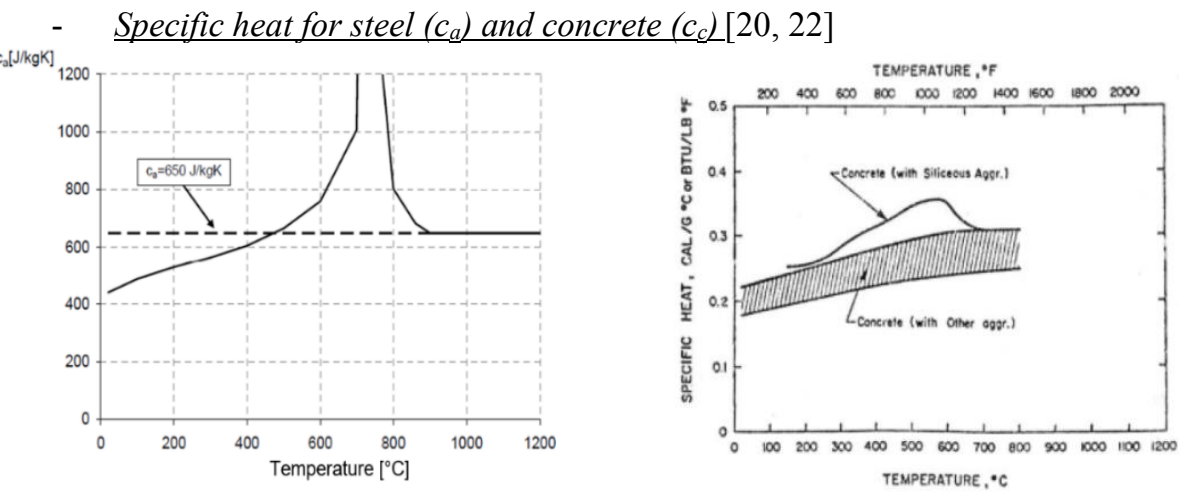

- $\quad$ Thermal conductivity for steel $\left(\lambda_{a}\right)$ and concrete $\left(\lambda_{c}\right)[1,21]$
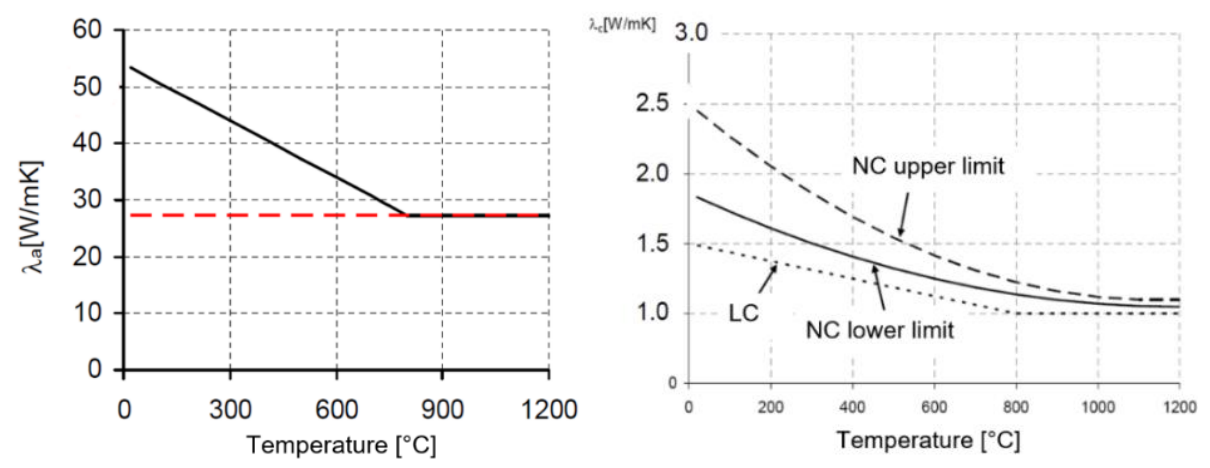

As far as concrete is concerned, the NC upper limit usually is representative of reinforced concrete while the lower curve is associated to the concrete itself. In absence of samples to be tested, the NC lower limit curve has been implemented.

- Density [23]: A value of $7850 \mathrm{~kg} / \mathrm{m}^{3}$ has been adopted for steel. As far as concrete is concerned, the trend reported below has been approximated as follows: constant and equal to $2300 \mathrm{~kg} / \mathrm{m}^{3}$ up to $700{ }^{\circ} \mathrm{C}$, then linear decrease between $700{ }^{\circ} \mathrm{C}$ and $800{ }^{\circ} \mathrm{C}$ up to $1400 \mathrm{~kg} / \mathrm{m}^{3}$ and constant in the remaining upper range.

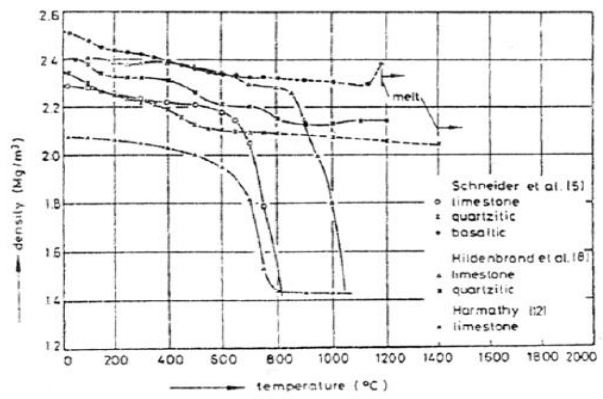

